\title{
MANAJEMEN SARANA DAN PRASARANA DALAM MENINGKATKAN PRODUKTIVITAS DI SEKOLAH DASAR
}

\author{
Rahmayani \\ SDIT Al-Fityan, Jalan Raya Sungai Kakap, Kecamatan Sungai Kakap, Kubu Raya \\ e-mail: arieyani1912@gmail.com
}

\begin{abstract}
Abstrak
Tujuan penelitian untuk mendeskripsikan manajemen sarana dan prasarana di Sekolah Dasar Islam Terpadu (SDIT) Al-Fityan Kubu Raya. Metode penelitian yang digunakan yaitu metode deskriptif kualitatif. Penelitian dilakukan di SDIT Al-Fityan Kubu Raya dengan subjek penelitian yaitu: kepala sekolah; wakil kepala sekolah bidang kesiswaan dan kurikulum; bendahara; serta staf tata usaha. Teknik pengumpulan data berupa wawancara, observasi, dan studi dokumentasi. Teknik analisis data menggunakan analisis deskriptif. Hasil penelitian menunjukkan bahwa: (1) Kebijakan perencanaan sarana dan prasarana disusun pada awal tahun dengan menganalisis kebutuhan; (2) Kebijakan pengadaan sarana dan prasarana sesuai dengan prosedur yang ada; (3) kebijakan pengorganisasian sarana dan prasarana sesuai dengan keputusan kepala sekolah; dan (4) pemeliharaan sarana dan prasarana cukup akuntabel.
\end{abstract}

Kata Kunci: manajemen, sarana dan prasarana, produktivitas sekolah.

\section{Abstract}

The purpose of the research was to describe the management of facilities and infrastructure at the Al-Fityan Kubu Raya Islamic Elementary School. The research method used descriptive method with a qualitative approach. The research was conducted at SDIT Al-Fityan Kubu Raya with the research subjects: the principal, the vice-principal of the student affairs and curriculum; treasurer; and administrative staff. Data collection techniques used interviews, observation, and documentation. The data analysis technique used descriptive analysis. The results of the research indicate that: (1) The planning policy for facilities and infrastructure are prepared at the beginning of the year by analyzing needs; (2) The policy for the procurement of facilities and infrastructure is in accordance with existing procedures; (3) The policy of organizing facilities and infrastructure in accordance with the decision of the principal; and (4) The maintenance of facilities and infrastructure is sufficiently accountable.

Keywords: management, facilities and infrastructure, school productivity.

\section{PENDAHULUAN}

Produktivitas sekolah yang baik tidak terlepas dari peran serta guru dengan kualitas output dan pendidikan yang baik. Produktivitas merupakan kemampuan untuk menghasilkan sesuatu yang apabila dikaitkan dengan kinerja, maka mengarah pada efektivitas dan efisiensi (Thomas, 2013). Untuk menjadikan sekolah yang produktif, perlu diperhatikan faktor-faktor yang mempunyai pengaruh atas tinggi-rendahnya produktivitas, diantaranya moral, etika kerja, motivasi, sikap, disiplin, kesehatan, kesempatan berprestasi, lingkungan, iklim 
kerja, teknologi, kepuasan, hubungan insani, tingkat pendidikan, kebijakan pemerintah, serta sarana dan prasarana. Seseorang akan mendapat pendidikan yang layak dan baik apabila sekolah memperhatikan banyak hal, baik manajemennya, sarana dan prasarananya, maupun sistem pembelajarannya (Kompri, 2014).

Organisasi (seperti sekolah) tentunya membutuhkan manajemen yang baik demi kelancaran dan tercapainya tujuan yang diinginkan. Untuk mencapai hal tersebut, tentunya membutuhkan sarana dan prasarana yang menunjang. Pendidikan yang berkualitas harus memiliki sarana dan prasarana yang memadai. Sarana dan prasarana pendidikan mempunyai peran penting karena mutu pendidikan dapat ditingkatkan melalui pengadaan sarana dan prasarana. Standar sarana dan prasarana diatur dalam Peraturan Menteri Pendidikan Nasional Republik Indonesia Nomor 24 Tahun 2007. Standarisasi sarana dan prasarana sekolah merupakan suatu penyesuaian bentuk, baik penyesuaian dalam hal spesifikasi, kualitas maupun kuantitas dengan kriteria minimum yang telah ditetapkan (Arifin, 2017). Penyediaan sarana dan prasarana kerja dimaksudkan untuk menunjang kegiatan sekolah agar mencapai hasil yang optimal. Hasil yang optimal tersebut merupakan prestasi kerja bagi sekolah termasuk didalamnya guru yang terlibat. Karena dengan adanya sarana dan prasarana yang memadai dapat menciptakan hasil yang lebih memuaskan dalam menunjang kegiatan belajarmengajar dan mencapai tujuan yang telah ditetapkan (Mujisuciningtyas, 2017; Legiwati, 2016; Aini dan Sudira. 2015; Arpan dan Marpanaji, 2015).

Sarana dan prasarana pendidikan merupakan komponen penting dalam pendidikan dan menjadi satu dari delapan standar nasional pendidikan. Begitu pentingnya sarana dan prasarana pendidikan sehingga setiap institusi berupaya untuk memenuhi standar sarana dan prasarana demi meningkatkan kualitas sekolah. Kelengkapan sarana dan prasarana merupakan salah satu daya tarik bagi calon peserta didik. Jenis-jenis sarana dan prasarana yang distandarkan tersebut meliputi satuan pendidikan, lahan, bangunan gedung, serta kelengkapan sarana dan prasarana (Matin, 2016). Proses belajar-mengajar (PBM) atau kegiatan belajar-mengajar (KBM) akan semakin sukses bila ditunjang dengan sarana dan 
prasarana sekolah yang memadai, sehingga pemerintah pun selalu berupaya untuk terus-menerus melengkapi sarana dan prasarana sekolah bagi seluruh jenjang tingkatan pendidikan, sehingga kekayaan fisik negara yang berupa sarana dan prasarana sekolah sangat besar.

Sarana dan prasarana sebagai bagian integral dari keseluruhan kegiatan pembelajaran di satuan pendidikan mempunyai fungsi dan peran dalam pencapaian kegiatan pembelajaran sesuai kurikulum satuan pendidikan. Supaya pemenuhan sarana dan prasarana tepat guna dan berdaya guna (efektif dan efisien), diperlukan suatu analisis kebutuhan yang tepat dalam perencanaan pemenuhannya (Prastyawan, 2016). Sarana dan prasarana yang mencukupi diharapkan luarannya akan mencapai tujuan awal dari sebuah lembaga pendidikan, namun agar sarana dan prasarana pendidikan tercukupi dan relevan dengan kebutuhan, maka perlunya pengkajian lebih jauh tentang manajemen sarana dan prasarana, supaya visi dan misi dari sekolah akan tercapai sesuai dengan perencanaan awal. Mengacu pada Peraturan Menteri Pendidikan Nasional Republik Indonesia Nomor 24 Tahun 2007, sekurang-kurangnya sekolah memiliki prasarana yang meliputi ruang kelas, ruang perpustakaan, laboratorium, ruang pimpinan, ruang guru, tempat beribadah, usaha kesehatan sekolah (UKS), dan lapangan olahraga.

Sarana pendidikan adalah peralatan dan perlengkapan yang secara langsung dipergunakan dan menunjang proses pendidikan, khususnya proses belajarmengajar seperti gedung, ruang kelas, meja, dan kursi serta alat-alat serta media pengajaran agar pencapaian tujuan pendidikan dapat berjalan dengan lancar, teratur, efektif, dan efisien (Heryati dan Muhsin, 2014). Prasarana pendidikan adalah semua perangkat kelengkapan dasar yang secara tidak langsung menunjang pelaksanaan proses pendidikan di sekolah (Prihatin, 2011). Dengan demikian, tujuan penelitian adalah untuk mendeskripsikan manajemen sarana dan prasarana di Sekolah Dasar Islam Terpadu (SDIT) Al-Fityan Kubu Raya. 


\section{METODE}

Metode penelitian yang digunakan yaitu metode deskriptif kualitatif. Penelitian dilakukan di SDIT Al-Fityan Kubu Raya yang beralamat di Desa Pal Sembilan, Kecamatan Sungai Kakap, Kabupaten Kubu Raya, Provinsi Kalimantan Barat. Pengumpulan data dilakukan dengan teknik observasi, wawancara, dan studi dokumentasi. Sumber data dalam penelitian yaitu kepala sekolah, wakil kepala sekolah bidang kesiswaan, wakil kepala sekolah bidang kurikulum, guru, dan staf tata usaha (TU). Analisis data menggunakan analisis deskriptif yang terdiri dari tiga jalur kegiatan, yaitu reduksi data, penyajian data, dan penarikan kesimpulan/verifikasi.

Instrumen wawancara mengenai manajemen sarana dan prasarana di SDIT Al-Fityan Kubu Raya terdiri dari 4 butir. Butir pertama yaitu tentang perencanaan sarana dan prasarana dalam meningkatkan produktivitas di SDIT Al-Fityan Kubu Raya yang meliputi: (1) Apakah untuk memenuhi kebutuhan perlengkapan sekolah telah dibuat perencanaannya? Jika ada, apakah tujuannya? (2) Apakah rencana pengembangan sarana dan prasarana dibuat program kerja? Jika ya, bagaimana proses pembuatan program kerjanya? (3) Apakah dalam rencana pengembangan sarana dan prasarana membentuk/melibatkan personel sekolah? Jika ya, siapa saja yang terlibat? (4) Bagaimana analisis kebutuhan dan penganggaran yang dilakukan untuk membuat perencanaan pengadaan sarana dan prasarana? dan (5) Jika dalam pelaksanaan program ternyata rencana tidak dapat berjalan dengan sempurna, apakah bapak/ibu merevisi perencanaan sarana dan prasarana? Jika dilakukan, bagaimana proses revisi dilakukan?

Butir kedua yaitu tentang pengadaan sarana dan prasarana dalam meningkatkan produktivitas di SDIT Al-Fityan Kubu Raya yang meliputi: (1) Apakah pengadaan sarana dan prasarana sekolah berdasarkan analisis kebutuhan? (2) Bagaimanakah mekanisme pengadaan sarana dan prasarana sekolah? Bagaimanakah cara memperoleh perlengkapan sekolah? dan (4) Bagaimana bentuk laporan pengadaan barang? Butir ketiga yaitu tentang pengorganisasian sarana dan prasarana dalam meningkatkan produktivitas di SDIT Al-Fityan Kubu Raya yang meliputi bagaimanakah prosedur pengorganisasian sarana dan 
prasarana sekolah? Butir keempat yaitu tentang pemeliharaan sarana dan prasarana dalam meningkatkan produktivitas di SDIT Al-Fityan Kubu Raya yang meliputi: (1) Apabila dalam proses pelaksanaan terdapat barang yang tidak bisa digunakan, apakah ada program pemeliharaan? (2) Apakah ada prosedur pemeliharaan sarana dan prasarana sekolah? (3) Bagaimanakah proses pemeliharaan sarana dan prasarana sekolah? (4) Siapakah yang bertanggung jawab langsung terhadap sarana dan prasarana sekolah? dan (5) Apakah semua peralatan di sekolah terpelihara dengan baik?

Instrumen observasi manajemen sarana prasarana di SDIT Al-Fityan Kubu Raya terlihat pada Tabel 1.

Tabel 1 Instrumen Observasi SDIT Al-Fityan

Fokus Observasi

Sarana dan prasarana yang dimiliki

\section{Hal yang Diobservasi}

\section{HASIL DAN PEMBAHASAN}

Berdasarkan wawancara bersama kepala sekolah, wakil kepala sekolah, dan bagian tata usaha (TU) diketahui bahwa untuk memenuhi kebutuhan perlengkapan sekolah dalam satu tahun ajaran, selalu dilakukan perencanaan dengan menganalisis semua kebutuhan. Tujuan diadakannya perencanaan untuk meningkatkan kualitas dan mutu pembelajaran. Perencanaan sarana dan prasarana direncanakan di awal tahun (Fauzan, 2018; Darmastuti, 2014) melalui program kerja setiap wakil kepala sekolah bersama guru. Perencanan sarana dan prasarana pendidikan merupakan suatu proses analisis dan penetapan kebutuhan yang diperlukan dalam proses pembelajaran sehingga muncul istilah kebutuhan yang diperlukan (primer) dan kebutuhan yang menunjang (Mustari, 2014).

Proses perencanaan sarana dan prasarana untuk satu tahun ajaran berikutnya dilaksanakan secara musyawarah. Sekolah melibatkan semua guru untuk perencanaan sarana dan prasarana sekolah. Pada saat membuat perencanaan disesuaikan dengan anggaran yang tersedia. Guru diberikan kesempatan oleh 
kepala sekolah untuk mengemukakan ide atau gagasan tentang sarana dan prasarana apa saja yang diperlukan untuk satu tahun (Arifin, 2017).

Langkah yang dilakukan dalam pengadaan sarana dan prasarana pendidikan yang pertama adalah penetapan. Penetapan yang dilakukan bersama pihak sekolah mengacu pada kebutuhan yang diprioritaskan untuk mendukung proses pembelajaran. Tujuan penetapan sarana dan prasarana untuk memenuhi kebutuhan proses pembelajaran di dalam kelas. Dengan demikian pengadaan sarana dan prasarana pendidikan dilakukan oleh pimpinan sekolah yang berlandaskan pada kesepakatan bersama dan dengan melihat kebutuhan-kebutuhan yang diperlukan sekolah di SDIT Al-Fityan Kubu Raya.

Pengadaan sarana dan prasarana di SDIT Al-Fityan Kubu Raya berdasarkan analisis kebutuhan beserta fungsinya sesuai dengan rencana yang telah disusun sebelumnya. Pengadaan sarana dan prasarana menyesuaikan dengan anggaran yang dimiliki oleh sekolah. Pengadaan sarana dan prasarana SDIT Al-Fityan Kubu Raya dilakukan dengan cara pembelian dari dana sarana dan prasarana siswa dan dari dana biaya operasional sekolah (BOS). SDIT Al-Fityan Kubu Raya berada dibawah yayasan Al-Fityan, maka untuk mengajukan pembelian atau pengadaan sarana dan prasarana pihak sekolah mengisi form pengajuan pembelian terlebih dahulu yang ditujukan kepada penanggung jawab pembelian dan Wakil Direktur 2. Setelah mendapat persetujuan, maka barang tersebut akan dibeli. Jika harga barang yang diajukan melebihi Rp2.000.000, maka dana akan ditransfer.

Pengadaan sarana dan prasarana merupakan fungsi operasional pertama di sekolah. Fungsi tersebut pada hakikatnya merupakan serangkaian kegiatan untuk menyediakan sarana dan prasarana di sekolah sesuai kebutuhan, baik berkaitan dengan jenis, spesifikasi, jumlah, waktu maupun tempat dengan harga, dan sumber yang dapat dipertanggungjawabkan. Pengadaan sarana dan prasarana pendidikan adalah kegiatan penyediaan semua jenis sarana dan prasarana sesuai dengan kebutuhan dalam rangka mencapai tujuan pendidikan yang telah ditetapkan sebelumnya (Matin, 2016). Cara memperoleh sarana dan prasarana yang ada di sekolah untuk menunjang kegiatan pembelajaran yaitu dengan cara membeli. Setiap pembelian perlengkapan diketahui oleh kepala sekolah. Semua 
barang yang dibeli akan dibuatkan laporan pengadaan sarana dan prasarana yang diketahui oleh kepala sekolah. Kegiatan pengadaan sarana dan prasarana sendiri juga mempunyai fungsi untuk mengatur dan menyelenggarakan terpenuhinya sarana dan prasarana yang dibutuhkan terkait dengan jenis, jumlah, kualitas, tempat, dan waktu yang dikehendaki (Arum, 2007).

Pengorganisasian sarana dan prasarana di SDIT Al-Fityan menjadi tanggung jawab kepala sekolah. Dengan memberi wewenang atau tugas kepada wakil kepala sekolah dalam hal sarana dan prasarana. Untuk sarana dan prasarana yang berkaitan dengan proses pembelajaran merupakan tanggung jawab wakil kepala sekolah bidang kurikulum, sedangkan sarana dan prasarana yang berkaitan dengan kegiatan ekstrakurikuler siswa menjadi tanggung jawab wakil kepala sekolah bidang kesiswaan. Bagian tata usaha memberikan label atau nomor pada setiap sarana dan prasarana yang dimiliki sekolah. Pengorganisasian juga merupakan penyatuan langkah dari seluruh kegiatan yang akan dilaksanakan oleh elemenelemen dalam suatu lembaga. Pengorganisasian sangat menentukan kelancaran jalannya pelaksanaan berupa pengaturan lebih lanjut mengenai kekuasaan, pengaturan, dan tanggung jawab. Dengan demikian setiap orang tahu akan kedudukan, tugasnya, fungsinya, pekerjaannya, dan tanggung jawabnya. Pengorganisasian sarana dan prasarana merupakan proses untuk menjelaskan secara rinci mengenai tujuan dari adanya sarana dan prasarana serta memberikan tanggung jawab kepada orang yang telah diberikan tugas sebagai penanggung jawab yang sudah terstruktur (Benty dan Gunawan, 2017).

Tim dosen Universitas Pendidikan Indonesia menjelaskan bahwa organisasi adalah suatu sistem interaksi antar-orang yang ditujukan untuk mencapai tujuan organisasi. Sistem tersebut memberikan arahan perilaku bagi anggota organisasi. Pengorganisasian adalah kemampuan pimpinan sebagai pengambil kebijakan pada birokrasi pemerintah dan kepala sekolah sebagai pimpinan kegiatan pembelajaran (Sagala, 2009). Pemeliharaan merupakan kegiatan yang dilakukan secara terusmenerus untuk menjaga agar barang milik sekolah selalu dalam keadaan baik dan siap untuk digunakan. Pemeliharaan sarana dan prasarana pendidikan memiliki 
peranan yang sangat penting karena dengan adanya pemeliharaan yang baik, maka penyelenggaraan pendidikan akan berjalan baik pula (Megasari, 2014).

Pemeliharaan mencakup segala daya upaya yang terus-menerus untuk mengusahakan agar sarana dan prasarana tetap dalam keadaan baik. Kegiatan pemeliharaan dimulai dari pemakaian barang, yaitu dengan cara hati-hati dalam menggunakannya (Rahayu dan Sutama, 2015; Kurniawati dan Sayuti, 2013). Pemeliharaan yang bersifat khusus harus dilakukan oleh petugas yang mempunyai keahlian khusus pula sesuai dengan jenis barang yang dimaksud. Semua perlengkapan sekolah bukan saja ditata sedemikian rupa melainkan juga dipelihara dengan sebaik-baiknya secara teratur agar selalu enak dipandang, mudah digunakan, dan tidak cepat rusak (Bafadal, 2008). Setiap sarana dan prasarana kegiatan selalu diadakan pengecekan. Ditinjau dari sifatnya, ada empat macam pemeliharaan, yaitu pemeliharaan yang bersifat pengecekan, pemeliharaan yang bersifat pencegahan, pemeliharaan yang bersifat perbaikan, dan perbaikan berat. Ditinjau dari waktu perbaikannya ada dua macam pemeliharaan, yaitu pemeliharaan sehari-hari dan pemeliharaan berkala (Matin, 2016).

Sarana dan prasarana sekolah harus terpelihara dengan baik. Agar sarana dan prasarana terpelihara dengan baik, maka harus dilakukan pengecekan dan perlengkapan sekolah disimpan pada satu ruangan. Setiap barang yang rusak akan dibuatkan form perbaikan. Form perbaikan yang sudah terdata akan dilaporkan ke bagian sarana dan prasarana yayasan Al-Fityan Kubu Raya. Kemudian bagian sarana dan prasarana akan melakukan pengecekan. Menurut Peraturan Menteri Pendidikan Nasional Republik Indonesia Nomor 24 Tahun 2007, SD/MI sekurang-kurangnya memiliki prasarana sebagai berikut: (1) Ruang kelas; (2) Ruang perpustakaan; (3) Laboratorium IPA; (4) Ruang pimpinan; (5) Ruang guru; (6) Tempat beribadah; (7) Ruang UKS; (8) Jamban; (9) Gudang; (10) Ruang sirkulasi; dan (11) Tempat bermain/berolahraga. 
Tabel 2 Sarana dan Prasarana SDIT Al-Fityan Kubu Raya

\begin{tabular}{lcccc}
\hline \multirow{2}{*}{ Jenis Prasarana } & \multirow{2}{*}{ Jumlah } & \multicolumn{2}{c}{ Ukuran (Meter) } & \multirow{2}{*}{ Kondisi } \\
\cline { 3 - 4 } & & Panjang & Lebar & \\
\hline Ruang teori/kelas & 10 & 8 & 6 & Baik \\
Ruang perpustakaan & 1 & 7 & 7 & Baik \\
Ruang kepala sekolah & 1 & 6 & 4 & Baik \\
Ruang guru & 2 & 8 & 6 & Baik \\
Kamar mandi/WC guru laki-laki & 1 & 2 & 1,5 & Baik \\
Kamar mandi/WC siswa laki-laki & 4 & 2 & 1,5 & Baik \\
Kamar mandi/WC guru perempuan & 1 & 2 & 1,5 & Baik \\
Kamar mandi/WC siswa perempuan & 4 & 2 & 1,5 & Baik \\
Gudang & 1 & 7 & 7 & Baik \\
Lapangan olahraga & 1 & 18 & 9 & Baik \\
Kantin & 1 & 6,5 & 10 & Baik \\
UKS & 1 & 6 & 4 & Baik \\
\hline
\end{tabular}

Berdasarkan peraturan Peraturan Menteri Pendidikan Nasional Republik Indonesia Nomor 24 Tahun 2007, SDIT Al-Fityan Kubu Raya dapat dikategorikan memiliki sarana dan prasarana dengan kondisi yang baik. Hasil penelitian yang dilakukan selaras dengan hasil beberapa penelitian yang telah dilakukan yang menyatakan bahwa sarana dan prasarana berada pada kategori baik (Simatupang dan Sitompul, 2018; Miski, 2015).

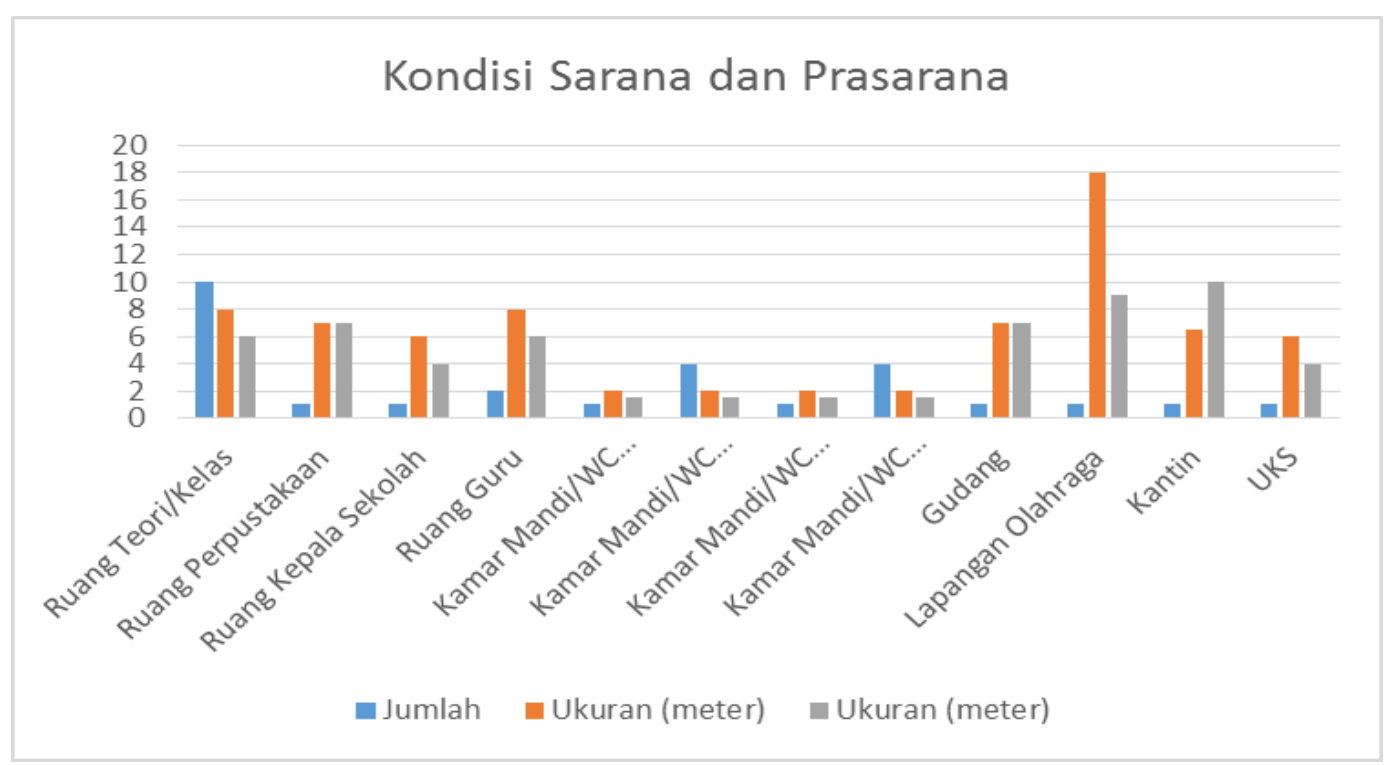

\section{Gambar 1 Kondisi Sarana dan Prasarana SDIT Al-Fityan Kubu Raya}

Berdasarkan Gambar 1, diketahui bahwa SDIT Al-Fityan Kubu Raya dapat dikategorikan sebagai sekolah yang memiliki prasarana yang cukup lengkap. 
Seluruh ruang kelas yang ada sesuai dengan jumlah rombongan belajar sehingga tidak ada kelas yang digunakan secara bergantian oleh rombongan belajar yang berbeda. Seluruh bangunan sekolah yang menunjang kelancaran pelaksanaan kegiatan belajar-mengajar di sekolah dalam kondisi baik. Begitu pula dengan sarana penunjang lain, seperti meja dan kursi siswa yang sesuai dengan jumlah siswa dalam kondisi baik sehingga kelancaran kegiatan belajar-mengajar dapat terjamin. Hasil penelitian yang dilakukan mendukung hasil penelitian sebelumnya yang menunjukkan bahwa fasilitas di Madrasah Aliyah Swasta Ar-Rosyidiyah Bandung sudah memadai (Sinta, 2019).

\section{SIMPULAN}

Berdasarkan hasil penelitian, maka majemen sarana dan prasarana dalam meningkatkan produktivitas di SDIT Al-Fityan Kubu Raya dapat disimpulkan: (1) Perencanaan sarana dan prasarana di SDIT Al-Fityan Kubu Raya telah dilaksanakan dengan mengadakan analisis kebutuhan dan disusun pada awal tahun ajaran; (2) Pengadaan sarana dan prasarana di SDIT Al-Fityan Kubu Raya sesuai dengan prosedur yang ada berdasarkan analisis kebutuhan dan estimasi biaya; (3) Pengorganisasian sarana dan prasarana di SDIT Al-Fityan Kubu Raya sesuai dengan keputusan kepala sekolah dengan memberi wewenang kepada wakil kepala sekolah untuk bertanggung jawab terhadap sarana dan prasarana yang ada; dan (4) Pemeliharaan sarana dan prasarana di SDIT Al-Fityan Kubu Raya cukup akuntabel.

\section{DAFTAR PUSTAKA}

Aini, S. N. \& Sudira, P. 2015. Pengaruh Strategi Pembelajaran, Gaya Belajar, Sarana Praktik, dan Media terhadap Hasil Belajar Patiseri SMK seGerbangkertasusila. Jurnal Pendidikan Vokasi, 5(1): 88-102.

Arifin, M. B. 2017. Sistem Penjaminan Mutu Pendidikan Teori \& Praktik. Yogyakarta: Ar-Ruzz Media.

Arpan, M. \& Marpanaji, E. 2015. Faktor-Faktor Eksternal yang Memengaruhi Hasil Belajar Pemrograman Komputer Mahasiswa PTIK STKIP PGRI Pontianak. Jurnal Pendidikan Vokasi, 5(2): 195-208.

Arum, W. S. A. 2007. Manajemen Sarana dan Prasarana Pendidikan. Jakarta: CV Multi Karya Mulia. 
Bafadal, I. 2008. Manajemen Perlengkapan Sekolah. Jakarta: PT Bumi Aksara.

Benty, D. D. N. \& Gunawan, I. 2017. Manajemen Pendidikan Suatu Pengantar Praktik. Bandung: Alfabeta.

Darmastuti, H. 2014. Manajemen Sarana dan Prasarana dalam Upaya Peningkatan Kualitas Pembelajaran pada Jurusan Teknik Komputer dan Informatika di SMK Negeri 2 Surabaya. Inspirasi Manajemen Pendidikan, 3(3): 9-20.

Fauzan, A. 2018. Manajemen Sarana dan Prasarana Pondok Pesantren Shuffah Hisbullah Natar Lampung Selatan. Jurnal Iqra': Kajian Ilmu Pendidikan, 3(1): 249-276.

Heryati, Y. \& Muhsin, M. 2014. Manajemen Sumber Daya Pendidikan. Bandung: Pustaka Setia.

Kompri. 2014. Manajemen Pendidikan 2. Bandung: Alfabeta.

Kurniawati, P. I. \& Sayuti, S. A. 2013. Manajemen Sarana dan Prasarana di SMK N 1 Kasihan Bantul. Jurnal Akuntabilitas Manajemen Pendidikan, 1(1): 98108.

Legiwati, N. 2016. Pengaruh Pemanfaatan Sarana dan Prasarana Pembelajaran dan Motivasi Belajar terhadap Hasil Belajar Siswa Kelas VII SMPN 3 Grati Satap Kabupaten Pasuruan. Jurnal Penelitian dan Pendidikan IPS, 10(2): 294-309.

Matin, F. N. 2016. Manajemen Sarana dan Prasarana Pendidikan Konsep dan Aplikasinya. Jakarta: PT Raja Grafindo Persada.

Megasari, R. 2014. Peningkatan Pengelolaan Sarana dan Prasarana Pendidikan untuk Meningkatkan Kualitas Pembelajaran di SMPN 5 Bukit Tinggi. Jurnal Administrasi Pendidikan, 2(1): 631-638.

Miski, R. 2015. Pengaruh Sarana dan Prasarana terhadap Hasil Belajar Siswa. Tadbir Muwahhid, 4(2): 69-73.

Mujisuciningtyas, N. 2017. Pengaruh Kemandirian Belajar dan Sarana Prasarana Pembelajaran terhadap Hasil Belajar Praktik di SMK Negeri 2 Tuban. Jurnal Ekonomi Pendidikan dan Kewirausahaan, 2(1): 103-115.

Mustari, M. 2014. Manajemen Pendidikan. Jakarta: Raja Grafindo Persada.

Peraturan Menteri Pendidikan Nasional Republik Indonesia Nomor 24 Tahun 2007 tentang Standar Sarana dan Prasarana untuk Sekolah Dasar/Madrasah Ibtidaiyah (SD/MI), Sekolah Menengah Pertama/Madrasah Tsanawiyah (SMP/MTs), dan Sekolah Menengah Atas/Madrasah Aliyah (SMA/MA) dalam http://repositori.kemdikbud.go.id/18715/1/Permendiknas-No.-24tahun-2007.pdf Diakses 14 September 2020.

Prastyawan. 2016. Manajemen Sarana dan Prasarana Pendidikan. Al Hikmah: Jurnal Studi Keislaman, 6(1): 33-46.

Prihatin, E. 2011. Teori Administrasi Pendidikan. Bandung: Alfabeta.

Rahayu, S. M. \& Sutama. 2015. Pengelolaan Sarana dan Prasarana Pendidikan Sekolah Menengah Pertama. Jurnal Varidika Kajian Penelitian Pendidikan, 27(2): 123-129.

Sagala, S. 2009. Administrasi Pendidikan Kontemporer. Bandung: Alfabeta.

Simatupang, A. C. \& Situmpol, A. F. 2018. Analisis Sarana dan Prasarana Laboratorium Biologi dan Pelaksanaan Kegiatan Praktikum Biologi dalam 
Mendukung Pembelajaran Biologi Kelas XI. Jurnal Pelita Pendidikan, 6(2): 109-115.

Sinta, I. M. 2019. Manajemen Sarana dan Prasarana. Jurnal Isema: Islamic Educational Management, 4(1): 77-92.

Thomas, P. 2013. Faktor Determinan Produktivitas Sekolah. Jurnal Penelitian dan Evaluasi Pendidikan, 17(1): 55-71.

Tim Dosen Universitas Pendidikan Indonesia. 2013. Manajemen Pendidikan. Bandung: Alfabeta. 